\title{
Decreasing Energy and Nutrient Intake During Hospitalization In Muhammadiyah Lamongan Hospital
}

\author{
Author \\ Amalia Rahma (Orcid ID. 0000-0003-2210 142X), \\ D N Suprihatiningrum (Orcid ID 0000-0003-2674-7420), \\ Widya Endirasari (Orcid ID 0000-0003-2842-983X) \\ Correspondence \\ Universitas Muhammadiyah Gresik, Jawa Timur, Indonesia \\ Muhammadiyah Lamongan Hospital, Jawa Timur, Indonesia \\ amaliarahma@umg.ac.id,dwinovri@umg.ac.id
}

\begin{abstract}
:
Malnutrition rates in inpatients are quite high and distributed in almost all hospitals for all types of diseases and socio-economic sufferers. This study aims to examine the nutritional status, total patient intake and factors that influence the total intake of new hospitalized patients at Muhammadiyah Lamongan Hospital. The study was conducted from November to December 2019 in the internal, surgical and Obgyn department of the Muhammadiyah Lamongan Hospital. A total of 80 patients were selected as samples using the accidental sampling technique. The results showed that $87.5 \%$ of patients were hospitalized due to non-communicable diseases such as diabetes mellitus, acute and chronic kidney failure, cirrhosis, acute myocardial infark and others. Only $12.5 \%$ are treated for infectious diseases such as tuberculosis, meningitis, diarrhea and others. Calculation of BMI in patients shows that $10 \%$ of patients are obese, $30 \%$ are overweight, $50 \%$ are normal and $10 \%$ are malnourished. 24-hour recall results showed that $100 \%$ of patients could not meet energy and nutrient requirements $(<80 \%$ of energy and nutrient demand figures). The average patient is only able to meet $24 \%$ of energy, $17 \%$ protein, $24 \%$ carbohydrates and $18 \%$ fat. As many as $35 \%$ of patients complained of nausea and $22.5 \%$ of them were accompanied by vomiting. The number of patients said that decreased appetite because abdominal pain (35\%), $25 \%$ patients experienced shortness of breath. Many patients complained that their bodies were weak / without strength (95\%). Appetite also decreased due to difficulty chewing (17.5\%) and difficulty swallowing (22.5\%). Physical condition like weak accompanied by other eating disorders can be the cause of the patient's decreased food intake. This has led to a decrease in nutritional status in patients due to inadequate energy and nutrient need (especially those who have to go through a long period of hospitalized).
\end{abstract}

Keywords: Malnutrition, intake, patient, hospitalization.

\section{Introduction}

Nutrition services are services that provided to patients based on clinical conditions, nutritional and metabolic status. Nutrition service activities at the hospital include outpatient nutrition care, inpatient nutrition care, food management, research and development (Aritonang, 2012). Patients treated in hospitals have special conditions. Patients separate themselves from the habits of daily life, especially in eating habits, not only the type of food served but the way to serve, place, time to eat, taste of food, large portions and types of food served all of which have an impact on the patient's food intake.
Received: 26 August 2021. Accepted: 23 December 2021.

Inadequate food intake for a long time will decrease nutritional status of patients (Dwiyanti et al. 2004).

Malnutrition during hospitalization is one of the problems encountered in efforts to cure the patient. The malnutrition rate in inpatients is quite high and evenly distributed in almost all hospitals for all types of diseases and socio-economic sufferers (Braunschweig et al., 2000s. Malnutrition can arise from before being hospitalized due to illness or inadequate nutrient intake, but not infrequently this malnutrition arises during hospitalization. Research conducted by McWhirter and Pennington shows that $40 \%$ of patients experience undernourish (lack of food) at the time of 
hospital admission and two-thirds of these patients run into weight loss during hospitalization. Factors causing reduced nutrient reserves in the body usually due to disease and nutrient deficiency and insufficient food intake, this will have an impact on complications (Anzar et al., 2013).

The type of diet will affect the amount of patient intake. The type of diet and form of food are influenced by the condition of the disease, the ability of the patient and the condition of the patient's digestive system. This study aims to examine the nutritional status, total intake of patients and factors that influence the total intake of new hospitalized patients. This research is expected to be useful to provide information on nutritional status and intake of patients who just entered the hospital as well as factors that often affect patient intakes.

\section{Methods}

\section{Design, time and place}

The research design was cross sectional study. The study was conducted from November to December 2019 in Muhammadiyah Lamongan Hospital.

\section{Number and sampling techniques}

A total of 80 patients were selected to be sampled using accidental sampling techniques. The inclusion criteria for male and female patients, have the risk of malnutrition based on nutritional screening at hospital admission and were willing to participate in this series of studies.

\section{Research Instruments}

The instruments required were MST screening forms, 24-hour recall forms, and metlines.

\section{Types and Data Collection Methods}

\section{Types of data}

Type of data collected is primary data obtained directly through interviews and observations to patients. Data collected includes data on characteristics of nutritional status data obtained from anthropometric measurements, that is body weight obtained by weighing measuring LILA using a scale (bathroom scale) and Dacin.

\section{Data Collection}

a) Preparation and Implementation
1. To coordinate and arrange permission to conduct research activities in the Muhammadiyah Lamongan Hospital.

2. Provide an explanation of the research plan and technical implementation as initial information on the research of the relevant agencies.

3. Retrieval of data is assisted by a 6th semester Nutrition Study Program student.

4. Fill in a letter of willingness to be a respondent to the patient's family.

5. Prepare research tools and instruments

6. Perform nutritional screening whether patients are at risk of malnutrition or not

7. And classify Carry out measurements of LILA and ULNA lengths which are then converted to body weight and height for determination of nutritional status (BMI).

\section{Processing Data}

Analysis Univariate analysis aims to explain or describe the patient's character such as age, sex, type of disease and nutritional status used to obtain an overview of each study variable. Bivariate analysis is used to describe the relationship between clinical physical condition, type of disease, type of diet and feeding route with total intake and nutritional status of patients.

\section{Results and Discussion \\ Respondents}

Characteristics Respondent / patient characteristics studied included gender, age, type of disease and nutritional status. Based on gender 55\% of respondents are male and $45 \%$ are female. Most respondents entered pre-elderly age with an average age of $53.12+2.5$ years by $60 \%$, followed by adulthood by $30 \%$ with an average age of $36.75+$ 10.3 years, as well as adolescents and the elderly respectively $-5 \%$ each (Table 1 ). 
Table 1. Characteristics of the respondent / patient

\begin{tabular}{lccc}
\hline & Characteristics & Number\% \\
\hline \multirow{2}{*}{ Gender } & Male & 44 & 55 \\
& Female & 36 & 45 \\
\hline \multirow{3}{*}{ Age } & Total & $\mathbf{8 0}$ & $\mathbf{1 0 0}$ \\
& Young & 4 & 5 \\
& Adults & 24 & 30 \\
& Pre-Elderly & 48 & 60 \\
& Elderly & 4 & 5 \\
\hline Diseases & Total & $\mathbf{8 0}$ & $\mathbf{1 0 0}$ \\
& Communicable disease & 70 & 87,5 \\
& Non-communicable diseases & 10 & 12.5 \\
\hline & Total & $\mathbf{8 0}$ & $\mathbf{1 0 0}$ \\
\hline
\end{tabular}

As many as $87.5 \%$ of patients hospitalized in internal, surgical and obstetric wards due to noncommunicable diseases such as diabetes mellitus, acute and chronic kidney failure, liver cirrhosis, acute myocardial infarction and others. Only $12.5 \%$ are treated for infectious diseases such as tuberculosis, meningitis, diarrhea and others.

\section{Nutritional Status of Patients}

Patients admitted for inpatient hospital after being severely malnourished or potentially having problems of nutrition during the treatment based on the results skirining assessment will be done directly by measuring LILA and ULNA to calculate BB and TB. Calculation of BMI in patients shows that $10 \%$ of patients are obese, $30 \%$ are overweight, $50 \%$ are normal and $10 \%$ are malnourished. This condition shows that most patients who are hospitalized have normal nutritional status and excess nutrition. Normal nutritional status conditions and more does not guarantee patients avoid malnutrition during hospitalization, because the intake may decrease dramatically during treatment. This study is not much different from that put forward by Daldiyono and Thaha (1998) who cite from several studies, predicting $40-55 \%$ of patients who are hospitalized are malnourished or at risk of malnutrition, $12 \%$ of which are severe malnutrition. On average $75 \%$ of the nutritional status of patients treated at the hospital will decrease compared to the nutritional status at the time of hospital admission.
Table 2. Nutritional status of the patient / respondent

\begin{tabular}{lcc}
\hline \multicolumn{1}{c}{ Nutritional Status } & Total & \% \\
\hline Underweight (BMI <18.5) & 8 & 10 \\
Normal & 40 & 50 \\
Overweight & 24 & 30 \\
Obesity & 8 & 10 \\
Total & 80 & 100 \\
\hline
\end{tabular}

\section{4-H-recall}

Based on 24-hour recall results, $100 \%$ of patients did not meet their energy and protein needs. The average patient is only able to provide $24+18 \%$ and $17+20 \%$. The average patient is only able to meet $24+34 \%$ carbohydrates and $18+22 \%$ fat needs.

Table 3. 24-hour recall results

\begin{tabular}{lcccc}
\hline \multirow{2}{*}{ Intake } & Mean(\%) & \multicolumn{3}{c}{$\begin{array}{c}\text { Number of patients } \\
\text { fulfilling energy and } \\
\text { nutrient requirements }\end{array}$} \\
\cline { 3 - 5 } & & $<80 \%$ & $80-$ & $>$ \\
& & & $100 \%$ & $110 \%$ \\
\hline Energy & $24 \pm 18 \%$ & 80 & 0 & 0 \\
Protein & $17 \pm 20 \%$. & 80 & 0 & 0 \\
Fat & $18 \pm 22 \%$ & 78 & 2 & 0 \\
KH & $24 \pm 34 \%$ & 76 & 4 & 0 \\
\hline
\end{tabular}

Based on research at Dr. Sarjito Hospital, it showed that subjects with insufficient energy intake had a 4.9 times greater risk of malnutrition compared to subjects with sufficient energy intake. This shows that nutritional support for patients treated in hospitals is needed. Patients who received proper nutritional support evidently experienced an average weight gain of $7.9 \%$ (Dwiyanti et al., 2004). The high risk is due to the high percentage of non-infectious diseases and 
medical therapy compared to two other hospitals, namely $80 \%$ and $43 \%$, respectively. Based on research Naber et al.(1997), it was found that patients who were infectious and non-infectious were at risk of experiencing malnutrition respectively 1.4 and 1.5 times. This means that the risk of patients suffering from non-infectious diseases is greater than those suffering from infectious diseases.

\section{Dietary history}

The emergence of various diseases, especially degenerative, is closely related to wrong eating habits. As many as $87.5 \%$ have the habit of eating three meals a day, the other $12.5 \%$ have the habit of eating twice a day. Based on interviews with other patients' eating habits listed in Table 4 and Table 5 to determine the consumption habits of fruits and vegetables.

Table 4. Patient eating habits

\begin{tabular}{lccc}
\hline \multicolumn{1}{c}{ Habits } & $\begin{array}{c}\text { Not a } \\
\text { habit } \\
(\boldsymbol{\%})\end{array}$ & $\begin{array}{c}\text { Rarely } \\
(\boldsymbol{\%})\end{array}$ & $\begin{array}{c}\text { Frequent } \\
(\boldsymbol{\%})\end{array}$ \\
\hline $\begin{array}{l}\text { Sweet foods } \\
\text { Sweet drinks } \\
\text { (coffee, tea }\end{array}$ & 25 & 27.5 & 42.5 \\
$\begin{array}{l}\text { and packaged } \\
\text { drinks) }\end{array}$ & & 35 & 40 \\
$\begin{array}{l}\text { Salty foods } \\
\text { and snacks } \\
\text { packaging }\end{array}$ & 15 & 30 & 55 \\
Fried & 12.5 & 30 & 57.5 \\
\hline
\end{tabular}

Unhealthy dietary patterns in the community are identical to the consumption of fast food or instant foods that are high in sodium are risk factors triggering the occurrence of noncommunicable diseases (PTM) such as Hypertension and Diabetic Mellitus (DM) (MOH, 2011). This also happened to patients at Muhammadiyah Lamongan Hospital, which of the sample of patients with non-communicable diseases was greater than those who experienced infectious diseases.
Table 5. Consumption habits of fruits and vegetables

\begin{tabular}{lcccc}
\hline $\begin{array}{l}\text { Consumption } \\
\text { habits }\end{array}$ & $\begin{array}{c}\text { very } \\
\text { rare }\end{array}$ & $\begin{array}{c}\text { Sometimes } \\
(\%)\end{array}$ & $\begin{array}{c}\text { Often } \\
\text { certain } \\
\text { types } \\
(\%)\end{array}$ & $\begin{array}{c}\text { Often } \\
\text { diverse } \\
\text { types } \\
(\%)\end{array}$ \\
\hline Fruits & 12.5 & 57.5 & 15 & 15 \\
Vegetables & 17.5 & 27.5 & 27.5 & 27,5 \\
\hline
\end{tabular}

\section{Types, forms and routes of feeding}

Type of diet, form and route of feeding are very dependent on the type of disease, health of the digestive system and the patient's clinical physical condition. The three types of diets that were most ordered at the nutrition installation for 40 patients were the TKTP diet followed by the DM diet and the low salt diet (Almatsier 2010). The most ordered form of food is soft food $(52.5 \%)$. As many as $30 \%$ of the food ordered is ordinary food, $12.5 \%$ filtered food and $5 \%$ liquid food. Most patients are still able to receive food orally (95\%) and only 5\% are helped with sonde (enteral feeding).

\section{General conditions of the patient}

Clinical physical conditions observed include blood pressure, nausea, vomiting, spasms, abdominal pain, headache, weakness, difficulty chewing and swallowing. Based on the results of blood pressure measurements obtained results of $47.5 \%$ of patients experiencing high blood pressure, $47.5 \%$ have a nominal blood pressure and $5 \%$ low blood pressure. As many as $35 \%$ of patients complained of nausea and $22.5 \%$ of them were accompanied by vomiting. As many as $35 \%$ complained of decreased appetite due to abdominal pain, $25 \%$ experienced shortness of breath. Many patients complained that their bodies were weak / without strength (95\%). Appetite also decreased due to difficulty chewing $(17.5 \%)$ and difficulty swallowing $(22.5 \%)$.

Weak physical condition in the respondent accompanied by other eating disorders can be the cause of the patient's decreased food intake. This has led to a decrease in nutritional status in patients (especially those who have to go through a long period of care) due to the unmet need for energy and nutrients (Braunchweigh et al. 2000; Muray, 2015). 
Conclusion

The nutritional status of new hospitalized patients in the internal, surgical and obstetric wards which is calculated based on the majority has normal nutritional status, while the intake of energy and macro nutrients (KH, protein and fat) of all in patients are categorized as severe deficits. The most common complaints submitted by patients that result in decreased appetite are weak body conditions, pain in the stomach and the presence of nausea and vomiting. This needs to be watched out for by hospital nutritionists, although patients have normal nutritional status at the beginning of hospital admission, patients have the potential to experience nutritional problems if the causes of decreased appetite are not addressed. One way to overcome the problem of intake is the form of food and route of administration by paying attention to the right type of diet according to the type of disease.

\section{References}

Almatsier S., 2010. Basic Principles of Nutrition. Jakarta: Gramedia Main Library.

Anzar J, Pratignyo B, Nazir M. 2013. Profile of the adequacy of food intake in hospitalization. Journal of Sari Pediatrics. 14 (6): 351-356.

Aritonang, Irianton. 2012. Food Management. Yogyakarta: Department of Nutrition Poltekkes.

Braunschweig C, Gomez S, and Sheean PM. 2000. Impact of declines in nutritional status on outcomes in adult patients hospitalized for more than 7 days. J Am Diet Assoc. 100 (1): 1316-1322.

Daldiyono and Thaha AR. 1998. Capita Selekta Clinical Nutrition. Jakarta: Indonesian Enteral and Parenteral Nutrition Association.

Dwiyanti D, Hadi H, Susetyowati. 2004. Effect of food intake on the incidence of malnutrition in hospitals. Journal Of Nutrition Clinics Indonesia, 1 (1): 17.
McWhirter JP, and Pennington CR. 1994. Incidence and recognition of malnutrition in hospital. British Medical Journal. 308: 945-8.

Ministry of Health of Indonesia . 2011. National strategy of applying consumption patterns and physical activity to prevent non-communicable diseases. Jakarta: Ministry of Health of the Republic of Indonesia

Muray MJ. 2015. Nutrition. STOELTING'S: Pharmacology \& Physiology in Anesthetic Practice. Issue 5. Pages 716-731. USA: Wolters Kluwer Health.

Naber THJ, T Schermer, A Bree, et al. 1997. Prevalence of Malnutrition in Nonsurigical Hospitalized Patients and Its Association with Disease Complication, Am J Clin Nutr. 66 (1): 1232-1239. 